\title{
La viabilidad de la ejecución de las reparaciones a favor de las víctimas en las sentencias de la Jurisdicción Especial de Paz ${ }^{1}$
}

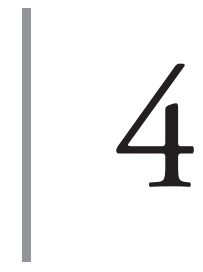

https://doi.org/10.21830/9789585284883.04

\author{
Manuel Bermúdez-Tapia ${ }^{2}$ \\ Universidad Privada San Juan Bautista \\ Paola Alexandra Sierra-Zamora ${ }^{3}$ \\ Escuela Militar de Cadetes "General José María Córdova” \\ Yarbey Arles Jaramillo Pérez ${ }^{4}$ \\ Escuela de Aviación del Ejército
}

\footnotetext{
1 Este capítulo hace parte del trabajo colaborativo de dos proyectos de investigación: 1) "Perspectivas en Derechos Humanos y Derecho Internacional Humanitario para el Ejército Nacional de Colombia" del Grupo de Investigación en Aviación Militar de la Escuela de Aviación del Ejército, registrado con el código COL0077618 y categorizado en C por Minciencias, y 2) "La legitimidad de las Fuerzas Militares en la geopolítica nacional e internacional de Colombia" del Grupo de Investigación en Ciencias Militares de la Escuela Militar de Cadetes "General José María Córdova", registrado con el código COL0082556 y categorizado en B por Minciencias. Los puntos de vista pertenecen a los autores y no reflejan necesariamente los de las instituciones participantes.

2 Abogado (magna cum laude) de la Pontificia Universidad Católica del Perú. Magíster en Derecho y $\mathrm{PhD}$ en Derecho por la Pontificia Universidad Católica de Argentina. Profesor-investigador de la Universidad Privada San Juan Bautista y profesor de la Facultad de Derecho de la Universidad Nacional Mayor de San Marcos. Orcid: http://orcid.org/0000-0003-1576-9464 - Contacto: manuel.bermudez@upsjb.edu.pe

3 Abogada de la Universidad Católica de Colombia. Magíster en Derechos Humanos, Democracia y Justicia Internacional por la Universitat de València, Espańa. PhD (c) del Programa de Derechos Humanos, Democracia y Justicia Internacional por la Universitat de Valéncia, España. Investigadora del grupo de investigación Ciencias Militares de la Escuela Militar de Cadetes "General José María Córdova”. Orcid: https://orcid.org/0000-0002-3146-7418. Contacto: paola.sierra@esmic.edu.co

4 Sargento Mayor del Ejército Nacional de Colombia. Pertenece al Arma de Aviación en la especialidad de Apoyo a Operaciones y en las subespecialidades de Control de Tránsito Aéreo y Seguridad Operacional. Se ha desempeñado como investigador de accidentes aéreos e investigador de factores humanos en actividades de aviación. Auditor de Seguridad Operacional (SMS) y auditor HSEQ. Ha adelantado estudios en el Centro de Estudios Aeronáuticos de la Unidad Administrativa Especial de Aeronáutica Civil de Colombia, en el Instituto de Investigación en Seguridad y Factores Humanos ESM de España, en la Universidad de Barcelona, en el Centro de Excelencia de Aviación del Ejército de los Estados Unidos y en el Augban College de los Estados Unidos. Orcid: https://orcid.org/0000-0002-68036291- contacto: yarvey.jaramillo@buzonejercito.mil.co
} 


\section{Introducción}

La tutela de los derechos humanos es un paradigma contemporáneo (Casal, 2008, p. 57) con orígenes tanto históricos como dogmáticos que se desarrollan a raíz de las nefastas consecuencias de la Segunda Guerra Mundial, en particular, por las acciones que provocaron la materialización de un Nuevo Orden Mundial con la creación de las Naciones Unidas y con los Juicios de Núremberg y los Juicios de Tokio —estos últimos muestran una especial importancia para el ámbito de la impartición de justicia, tema central del presente texto- (Liñán Lafuente, 2015, p. 94)

Sobre las consecuencias de una situación de extrema gravedad como lo fue la Segunda Gran Guerra, se han podido integrar elementos que involucran la coordinación y acción de varios Estados, gracias a lo cual se generó una politica internacional sumamente importante, que se ha tomado como referente en el ámbito interno de cada uno de los Estados del mundo (Figueroa, 2012, p. 16). Dicha política internacional ha incidido en la mejora de los sistemas de impartición y de administración de justicia, en función de la prevalencia de principios de orden constitucional y procesal a favor de los ciudadanos.

Sin embargo, uno de los elementos más importantes de este sistema radica en la evaluación de la efectividad y eficacia de las sentencias judiciales (Escudero Herrera, 2005, p. 106), las cuales deben evaluar elementos procesales, sustantivos, aplicativos y vinculantes del Estado (respecto de la administración pública) y de terceras personas. Por ello, una sentencia actúa también como un referente importante en un contexto de tutela de derechos humanos en el ámbito internacional, que repercute en el ámbito nacional cuando se debe ponderar una acción directa a favor del ciudadano como la reparación de un daño provocado al estar inmerso en el conflicto armado interno librado entre el Gobierno nacional y las guerrillas de Colombia (Sierra-Zamora \& Cubides-Cárdenas, 2018). En efecto, estas han sido varias y han desarrollado acciones específicas que no quedaron correctamente delimitadas en el Acuerdo Final de Paz del 2016, principalmente porque se ha asumido que las FARC-EP constituyen el principal referente opuesto al Gobierno nacional.

Esta situación constituye un evento contradictorio para los fines del mantenimiento de la paz en el país, porque sus propias entidades estatales no podrán cumplir los objetivos trazados, debido a que la reparación es un 
elemento sumamente complicado de atender. Frente a esto, se hace un análisis de elementos de naturaleza constitucional, procesal y de tutela de derechos humanos, sobre la base de una estructura que enfatiza la priorización de principios de orden constitucional y procesal en la evaluación de un expediente judicial en el cual se examina un daño y se determina una reparación.

\section{El derecho a la tutela judicial efectiva $y$ al debido proceso}

Ambos principios se consideran complementarios e interdependientes entre sí, especialmente, porque logran vincular los demás principios procesales y constitucionales aplicables al desarrollo y trámite de todo expediente judicial en cualquier jurisdicción (Ramírez Gómez, 1999).

Por sus alcances naturales es que las constituciones políticas de los Estados desarrollan su regulación en el ámbito normativo y vinculan todas las entidades relacionadas con la función y el servicio público de impartición y administración de justicia. De este modo, se establece como regla básica el control del poder que establece la Constitución y establece la relación entre el Estado y sus ciudadanos, en función de la tutela de las libertades de estos, así como el control y la delimitación de competencias de las entidades que conforman la administración pública (García de Enterría, 1982, p. 87).

Esta vinculación de elementos determinada por la Constitución debe ser analizada tanto a nivel internacional como a nivel reglamentario en el ámbito nacional, por ello se hace el presente estudio en función de la tutela de los derechos humanos, por cuanto no resulta viable ejecutar solo una evaluación particular para la realidad normativa colombiana (Rojas Rojas, 2007, p. 231).

De este modo, los tratados internacionales sobre derechos humanos que conducen a la nación colombiana a ejecutar políticas de Estado permiten desarrollar una actividad jurisdiccional que respete el orden constitucional mencionado y, si en eventualmente surge alguna situación negativa, se establecen los mecanismos de solución mediante la aplicabilidad de una normatividad supranacional.

En el ámbito nacional, la interpretación de los tratados internacionales sobre derechos humanos y lo estipulado en la Constitución se convierten en 
elementos fundamentales para el desarrollo de una normatividad con aspectos sustantivos y procesales que vinculan a todas las entidades de naturaleza jurisdiccional, a toda la administración pública (en general) y a toda la población.

Consecuentemente se permite llevar a cabo una interpretación que ejecuta un alcance integrado, superando los límites (naturales) que podría haber ejecutado el legislador nacional respecto de situaciones no previstas o planificadas en la época de promulgación de una norma y permitiendo que el juez pueda desarrollar una actividad interpretativa y funcional que permita la tutela de los derechos de los ciudadanos en un Estado de derecho (García López, 2014, p. 79).

El formalismo tradicional en el cual se desarrolla la actividad jurisdiccional en este sentido queda superado en función de elementos ya existentes que permiten una mejor adaptabilidad a las nuevas condiciones que deben ejecutar las entidades que imparten y administran justicia. Esto sucede así en particular para el caso de la JEP, por cuanto su institucionalidad está en evaluación y será un elemento vital para garantizar la legitimidad de la paz en los próximos años. Sin embargo, todo este contexto no puede entenderse mientras se excluya la materialización de una verdad y una justicia en función de la evaluación de los hechos y elementos probatorios que se exponen en un proceso judicial. Por tal razón, es posible señalar que el acceso a un proceso judicial que genere la vinculación del empleo de los principios constitucionales y procesales de la tutela judicial efectiva y del debido proceso no implica siempre un resultado positivo a favor del ciudadano (Calaza López, 2011).

Se debe tener en cuenta, en este contexto, que el ciudadano debe acreditar la afectación de sus derechos en el ámbito del seguimiento de un proceso en la JEP y, por tanto, deberá ser escuchado, deberá presentar y actuar sus medios probatorios y deberá acreditar el nivel de vulneración y vulnerabilidad provocado por haber estado en el conflicto armado interno colombiano (González Martínez et al., 2018). En la misma medida, este ciudadano deberá tomar conocimiento de los argumentos del Estado y de cómo este ejecuta su defensa a efectos de poder desacreditar los puntos contradictorios que estime conveniente y así pueda acreditar una verdad real (Guzmán, 2018), que permita la materialización de una verdad procesal que finalmente permitirá la emisión de una sentencia justa, proporcional y funcional al caso en evaluación. 
De acuerdo con lo anterior, la sentencia se convierte en un elemento de suma importancia, porque tiene una condición que justifica la decisión del juez en función a lo evaluado y por ello la ejecución de su contenido resulta ser un factor de suma importancia, porque lamentablemente se ha relacionado solo con una compensación económica a favor de la víctima por el daño ocasionado. Sin embargo, la materialización de una compensación económica no necesariamente repara el daño, ante lo cual ubicamos un elemento que merece ser ampliado y especificado: si se establece como patrón general el otorgamiento de una compensación económica a todas las víctimas del conflicto armado interno, surge de modo inmediato el problema de cómo se atenderá económicamente esta condición (Rincón, 2010, p. 126)

El riesgo de generar una situación declarativa permite detallar los alcances aplicativos de la JEP porque el Gobierno Nacional no podrá asumir en forma objetiva, todos los requerimientos que ejecutan un gasto público que incide en el presupuesto de la república.

Finalmente, la evaluación de una situación muy compleja producto del conflicto armado interno provocará un proceso judicial que no necesariamente resulte eficaz, por el contrario, las consecuencias pueden ser sumamente negativas para la legitimidad e institucionalidad democrática en Colombia (Hoyos Vásquez, 2007, p. 127). Por tanto, la efectividad de las sentencias requiere que, en primer término, el Gobierno nacional pueda asumir el compromiso de apoyar, respaldar y complementar la actividad que ejecutará la JEP (Pabón Parra, 2018). Solo de esta manera es posible desarrollar una ejecución de sentencias en la JEP que podría desarrollar un nuevo derecho surgido en función de las condiciones particulares y especiales de Colombia en la etapa posacuerdo: el derecho de prestación de una justicia especial que garantice la paz de forma efectiva, directa y sostenida en el tiempo.

Tal situación exige la articulación de todos los entes que conforman la administración pública, para poder desarrollar un marco normativo complementario a la sentencia que desarrolle la JEP y que pueda atender el inconveniente material de la insuficiencia de presupuesto público, para atender así la obligatoriedad de reparar el daño provocado en el ciudadano a raíz del conflicto armado interno. 


\section{La identificación de la víctima en el trámite procesal de la JEP}

Tomando en cuenta el análisis realizado en el punto preliminar, la identificación de la víctima resulta un asunto sumamente especial, porque implica:

a. Reconocer a una "persona" o "conjunto de personas" que directa o indirectamente han sido afectadas por el conflicto armado interno.

b. Reconocer un nivel de daño y conocer su alcance, con el fin de identificar el modo en que se debe ejecutar su reparación.

c. Reconocer el contexto en el cual se debe identificar a todas las víctimas del conflicto armado interno, porque en este ámbito no solo se ubican los civiles, sino también los integrantes de las Fuerzas Militares, que se han visto afectados por las acciones de las guerrillas durante todo el conflicto.

Por tanto, el empleo de una doctrina que proviene de la criminología es un referente clave, porque ello asiste de una mejor manera al ámbito procesal y procedimental en función de la evaluación de los alcances de una sentencia, con lo cual se recupera el carácter humano de la víctima, usualmente abandonada por el Estado y por el juez (García Pablos de Molina, 1994, p. 267)

Sin embargo, producto de las propias situaciones generadas en el conflicto armado interno en Colombia (Álvarez Calderón \& Duque Cruz, 2020), debemos tener presente que la víctima no está limitada a la relación con el "sujeto pasivo, neutro, estático que no contribuía en nada al hecho criminal" (Cuarezma Terán, 1996, p. 299), porque esencialmente esto debe acreditarse en el proceso judicial.

Bajo estos alcances, podemos, entonces, especificar lo siguiente:

a. No resulta necesario señalar la "condición de relación" entre los hechos vinculados con el conflicto armado interno y la víctima en la JEP, porque se debe tener presente el alcance de la condición de víctima indirecta, especialmente, en función de la sucesión de la condición procesal de la víctima por parte de sus deudos o representantes legales.

b. Una persona puede ser identificada y vinculada a un nivel de participación en las acciones propias del conflicto armado interno y ello no desvaloriza su condición de víctima. 
c. El alcance del "daño" debe ser evaluado en relación con elementos objetivos, los cuales pueden ser tan amplios como complejos de evaluar.

En este sentido, es posible identificar situaciones propias del desplazamiento forzado, la ejecución de actos de violencia de naturaleza sexual contra las víctimas o sus familiares o la obligación de ejecutar actividades laborales forzadas, por ejemplo, la ejecución de actos de sembrado o cosecha de cultivos de coca o amapola.

\section{La víctima del conflicto armado interno en la etapa del posacuerdo}

Tomando en cuenta el contexto complejo que resulta de la evaluación de la JEP, el empleo de la victimología resulta ser sumamente necesario, en particular porque se complementa con el desarrollo doctrinario en la especialidad penal a nivel comparado. Por tanto, resulta funcional que la JEP pueda tener en cuenta los siguientes elementos provenientes de la victimología en el desarrollo de sus funciones para garantizar su propia legitimidad:

a. Acentuar la pulcritud en el desarrollo de los procedimientos procesales y jurisdiccionales desarrollados con el fin de prevenir, como elemento básico y prioritario, el retorno del conflicto armado interno.

b. Desarrollar una práctica jurisdiccional eficiente que impida que se agudice con el tiempo la condición de víctima en mérito al daño que esta ha sufrido, porque entonces este puede resultar irreparable.

c. Desarrollar un nivel de efectividad en el trámite de los procesos judiciales que permita aminorar el impacto negativo del daño en la víctima, planteando alternativas viables para asignar una reparación que pueda ser admitida o valorada positivamente por parte de la víctima (Moreno, 2014).

Sin embargo, esto no permite evaluar el verdadero alcance del sujeto procesal que ha ejecutado el daño y, por tanto, surge una cuestión importante: ¿Cómo establecer la reparación a favor de la víctima si el sujeto activo del delito no es delimitado objetivamente? 


\section{Elementos procesales penales y civiles en la determinación de la reparación en la JEP}

Tomando en cuenta que la reparación que deberá desarrollar la JEP en la sentencia a ser impuesta tiene elementos teóricos y aplicativos de las especialidades del derecho civil y penal, es posible enfatizar su carácter instrumental para la presente evaluación temática (Taranilla, 2013, p. 63). Con base en esta referencia es posible establecer lo siguiente:

1. Para la determinación de una responsabilidad en la fundamentación de una sentencia judicial, se deben evaluar, en primer término, las acciones ejecutadas por el sujeto activo del delito de acuerdo con la acusación y los argumentos de defensa del imputado, porque sobre este límite impuesto por las partes procesales el juez debe evaluar los hechos para así identificar el "daño".

2. La determinación e identificación del alcance de un "daño" debe estar vinculada a una referencia que asuma su compensación, razón por la cual es necesario que el propio Estado garantice la sostenibilidad de las actividades de la JEP.

3. Se debe tener en cuenta que a raíz del conflicto armado interno, resulta imposible generar una "reparación" en cada uno de los procesos en trámite en la JEP, porque muchos de los elementos que serán analizados no podrán ser validados, corroborados o eventualmente contrastados y, en consecuencia, la actividad probatoria puede ser limitada.

\section{Condiciones especiales para la ejecución de sentencias en la JEP}

Sobre la premisa de que las decisiones judiciales contenidas en una sentencia implican la ejecución de sus disposiciones, conforme a la naturaleza procesal de la cosa juzgada y a la tutela de los derechos reconocidos como afectados en el proceso judicial, es importante recordar que no siempre será posible ejecutar una total satisfacción para una víctima, al menos en el ámbito procesal y judicial. En consecuencia, resulta necesario analizar los siguientes elementos: 
a. La condición de cosa juzgada implica la finalización de la etapa judicial, por lo tanto, se han determinado las condiciones en las cuales se han juzgado los "hechos" expuestos por las partes procesales y se ha determinado una consecuencia en el ámbito jurídico que generará condiciones en ambas partes procesales. De este modo, a una parte se le impondrá una condición negativa y a la otra se le deberá reparar el daño provocado.

b. Las decisiones de los órganos jurisdiccionales de la JEP, al igual que en el ámbito del sistema judicial ordinario o constitucional, son el resultado del desarrollo del principio de intangibilidad, por lo cual su condición no puede ser modificada o incumplida, puesto que ello garantiza una condición complementaria: la seguridad jurídica que la administración pública debe garantizar en un Estado de derecho.

c. La tutela judicial efectiva y el desarrollo del debido proceso se convierten en elementos procesales y procedimentales que imponen una condición favorable a todo ciudadano, ya que le permite a este último demostrar una condición que lo afectó en sus derechos, y le impone una condición superior al Estado para establecer una condición favorable a la reparación del daño, así como ejecutar una acción negativa y punitiva contra quien ejecutó el hecho ilícito (BermúdezTapia, 2010).

d. Se requiere que la sentencia tenga una condición procesal "fundada". De este modo, se exige que el Estado, a través de sus órganos jurisdiccionales, pueda atender una pretensión expuesta en un documento de carácter formal y procesal que provoque un proceso judicial correcto y en los términos de un debido proceso. Sobre dicha pretensión, se articulan las normas de carácter sustantivo y procesal que son empleadas por los abogados y jueces (según las instancias) hasta la determinación de una verdad material y procesal que es contenida y explicada en la sentencia.

e. Se requiere que la decisión esté debidamente motivada y exponga los elementos probatorios y de hecho expuestos en el proceso judicial, porque no basta con la determinación de una responsabilidad 
en la ejecución de los hechos investigados y evaluados, sino que la decisión judicial debe tener la legitimidad y el amparo suficientes para poder sostenerse ante cualquier situación de contradicción (en lo real) o de impugnación (en lo procesal y en lo judicial).

Bajo estos alcances se procura que la decisión judicial no tenga ningún elemento negativo que pudiera provocar su incumplimiento, ni que contenga un elemento arbitrario ajeno al ámbito evaluado en el propio expediente judicial. Lo anterior favorece la institucionalidad de la JEP, porque de este modo la atención de los hechos, de los fundamentos y argumentos expuestos en el trámite del proceso judicial serán objetivos y garantizarán una evaluación correcta, acorde a los contenidos y objetivos de un Estado de derecho democrático y social que prioriza la tutela de derechos de sus ciudadanos.

\section{El executio en las sentencias de la JEP}

Derivado de lo desarrollado hasta aquí, la facultad de ejecutar las decisiones judiciales es una prerrogativa de los órganos jurisdiccionales. En este caso, la JEP dispone de esta facultad, porque solo así se garantizan los principios de orden constitucional y procesal a favor de los ciudadanos en el trámite de un proceso judicial (Cujabante Villamil, 2019). Tal facultad se desarrolla en tres niveles:

a. Respecto de los contenidos que deben ejecutarse en cuanto a de las partes procesales.

Un alcance que permite identificar a cada parte, y conforme la propia naturaleza de la JEP, se debe tener presente la obligatoriedad de garantizar:

i. La progresividad de los derechos humanos.

ii. La generación de una interpretación interdependiente con otros valores y principios de orden constitucional y procesal a favor de la parte considerada víctima en el proceso. 
iii. La comunicación de los vacíos normativos y situaciones condicionales negativas a los órganos estatales para que estos puedan atender el carácter inalienable de lo dispuesto en la sentencia conforme su fundamento en los derechos humanos.

b. Respecto de los contenidos que deben ser acatados por las entidades de la administración pública.

Vinculado, sobre todo, al contexto administrativo y procedimental que deberá ser dispuesto en la propia sentencia judicial, por cuanto una omisión o una imprecisión puede provocar la inejecutabilidad o la demora en ejecutar lo decidido.

c. Respecto de la obligación de evaluar, fiscalizar y hacer seguimiento a sus decisiones.

De este modo, se permite superar la temporalidad que impone una sentencia judicial (Bermúdez-Tapia, 2018) y que eventualmente queda sujeta a la discrecionalidad de las partes, factor que es referencial en la jurisdicción ordinaria del poder judicial y que no puede ser admitida en la JEP.

\section{Referencias}

Álvarez Calderón, C. E., \& Duque Cruz, F. A. (2020). Oportunidades para las Fuerzas Militares de Colombia en operaciones multidimensionales de mantenimiento de paz. Revista Cientifica General José María Córdova, 18(29), 87-109. https://doi.org/10.21830/19006586.542

Bermúdez-Tapia, M. (2010). La eficacia del principio del debido proceso como garantía en un proceso sin dilaciones. RAE, Revista de Análisis Especializado en Jurisprudencia, 26, 77-85.

Bermúdez-Tapia, M. (2018). El plazo, la caducidad y las vicisitudes en el trámite de un proceso judicial. Gaceta Civil \& Procesal Civil, 58, 271-276.

Calaza López, S. (2011). El binomio procesal, derecho de acción-derecho de defensa: desde la concepción clásica romana hasta la actualidad. Dykinson.

Casal, J. (2008). Los derechos humanos y su protección: estudio sobre derechos humanos y derechos fundamentales. Universidad Católica Andrés Bello.

Cuarezma Terán, S. J. (1996). La victimología. Estudios básicos de derechos humanos (tomo v). Instituto Interamericano de Derechos Humanos.

Cujabante Villamil, X. (2019). La disciplina de las relaciones internacionales en Brasil: un análisis desde la sociología de la ciencia. Revista Cientifica General José María Córdova, 17(26), 289-305. https://doi.org/10.21830/19006586.417 
Escudero Herrera, M. (2005). Los obstáculos a la efectividad de las sentencias en el contencioso-administrativo y sus soluciones. Dykinson.

Figueroa, U. (2012). El sistema internacional y los derechos humanos. RIL Editores.

García de Enterría, E. (1982). Curso de derecho administrativo. Editorial Cívitas.

García López, L. (2014). El juez y el precedente: hacia una reinterpretación de la separación de poderes. Vniversitas, 63(128), 79-120. https://doi.org/10.11144/Javeriana.VJ128.jphr

García Pablos de Molina, A. (1994). Criminología: una introducción a sus fundamentos teóricos para juristas. Tirant lo Blanch.

González Martínez, M., Quintero Cordero, S., \& Ripoll De Castro, A. (2018). La seguridad en la Alianza del Pacífico. Revista Cientifica General José María Córdova, 16(23), pp. 63-80. https://doi.org/10.21830/19006586.102

Guzmán, N. (2018). La verdad en el proceso penal: una contribución a la epistemología jurídica. Didot Imprenta.

Hoyos Vásquez, G. (2007). Las víctimas frente a la búsqueda de la verdad y reparación en Colombia. Pontificia Universidad Javeriana.

Liñán Lafuente, A. (2015). El crimen contra la humanidad. Dykinson.

Moreno, M. (2014). ¿Quién teme a la victimidad? El debate identitario en victimología. Revista de Derecho Penal y Criminología, 3(12), 343-404.

Pabón Parra, P. (2018). Procedimiento penal especial abreviado y acusador privado: Ley 1826 de 2017. Doctrina y Ley.

Ramírez Gómez, J. (1999). Principios constitucionales del derecho procesal: investigación en torno a la Constitución Política de 1991. Señal Editora.

Rincón, T. (2010). Verdad, justicia y reparación: la justicia de la justicia transicional. Universidad del Rosario.

Rojas Rojas, C. (2007) Conflictos morales y derechos humanos en Colombia. Universidad de Caldas.

Sierra-Zamora, P. A., \& Cubides-Cárdenas, J. A. (2018). Derechos humanos en Colombia: a raiz del conflicto armado con las FARC [Documento de trabajo]. OSF Home. https://doi. org/10.17605/OSF.IO/CWK56

Taranilla, R. (2013). El género de la sentencia judicial: un análisis contrastivo del relato de hechos probados en el orden civil y en el orden penal. Ibérica: Revista de la Asociación Europea de Lenguas para Fines Especificos ( AELFE), 29, 63-82. 